\title{
Organizational and technological cycle of life of a construction object
}

\author{
Muhammet Fakhratov ${ }^{1, *}$, Vitaly Chulkov ${ }^{1}$, Dmitry Fayzullin ${ }^{1}$, and Salavat Zaidullin ${ }^{1}$ \\ ${ }^{1}$ Moscow State University of Civil Engineering, 129337, 26, Yaroslavskoye Shosse, Moscow, Russia
}

\begin{abstract}
During the life cycle, the state of an object is modified. The information for stepwise and phased study of innovation processes is characterized as local and torn in time, while the life cycle approach regards the process of creating and developing technological innovations as a dynamically synchronized system. The development of organizational and technological systems is being implemented in two directions: the improvement of basic and the creation of fundamentally new technologies. The life cycles of all objects, processes and systems are built on one info graphic model: any life cycle begins with the birth, passes through the stages of growth, maturity, decay and decline. Therefore, it is advisable to consider the innovative investment and construction life cycle of an object as a combination of a series of successive stages (cycles). They are subcycles during the period from the beginning of the idea of the initial design and construction of an object until the demolition, complete disassembly, disposal of construction and demolition waste $(\mathrm{CDW})$ and non-recyclable parts of them.
\end{abstract}

\section{Introduction}

Temporary, resource and organizational synchronization of all processes and production stages is possible on the basis of life cycles of innovation processes, products and systems. Local information torn in time is characteristic for stepwise and phased study of innovation processes, while the life cycle approach regards the process of creating and developing technological innovations as a dynamically synchronized system.

Innovation activity consists of a series of events combined into one logical chain. Each component of this chain (the innovation cycle stage) has its own development logic, its own laws and features. Connecting together, research, development and technological development, investment and financial, marketing activities, production facilities and organizational structures are subordinated to one main goal - the creation of innovation [1].

Originating in the depths of marketing research, the life cycles of market goods (norms, products and services), demand and technology in a short time have occupied a dominant position in the study of economic objects, processes and systems. The concepts of the life cycles of organizations, branches of industrial production, construction sites and structures, machines and mechanisms, processes and procedures have gained significant development.

\footnotetext{
* Corresponding author: aljurgaitis@gmail.com, fayzdim@mail.ru
} 
For the study of innovation, the life cycles of a new product, a new technique, technology and innovative organizations as open systems are most important.

The most productive modern idea of life cycles is the concept of large technological systems, including the evolution and transformation of technologies as economic objects. The study of the life cycles of large technological systems leads to the theory of generations of technics and technology, developing in the framework of both the traditional and the new technological paradigm.

\section{Methods}

The development of organizational and technological systems is being implemented in two directions: the improvement of basic and the creation of fundamentally new technologies. With the improvement and modernization of technologies, their transition to the stage of maturity and saturation of the market with this commodity, further technological development within the framework of the old paradigm becomes unprofitable, volume of sales and profits fall. In the depths of the existing technological structures, fundamentally new solutions, "breakthrough" technologies emerge, which lays the foundation for new technological structures, industries and branches [2].

The life cycles of all objects, processes and systems are built according to a single infographic model: any life cycle begins with the birth, passes through the growth, maturity, wilt and decline stages (Figure 1).

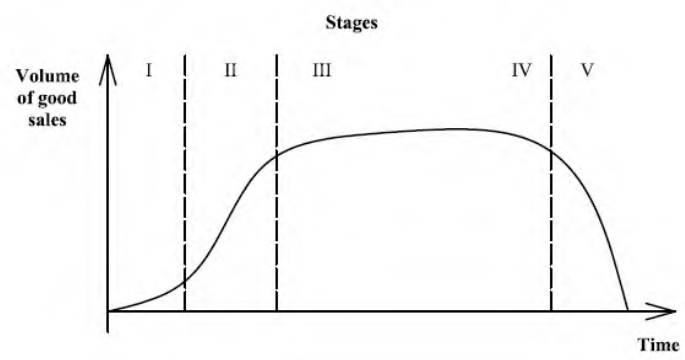

Fig. 1. The life cycle of an object, process or system. I - the stage of origin and the beginning of growth; II - rapid growth; III - growth retardation, maturity; IV - stabilization; V - wilting, aging, decay, end of life cycle.

The infographic model indicated in Figure 1 adequately sets the dynamics and structure of the life cycle of numerous objects of innovation management: innovative enterprises, new equipment and technology, new market goods (norms, products and services). The concept of the life cycle and its model (Fig. 1) provides: accounting for the use of various resources (including the time factor, material, information and financial flows); identification of the central trend of the process; visualization of the dynamics of transformations; process deployment logic; the possibility of using alternative forecasting methods; identification of the relationship of different objects.

The concept of the life cycle requires the study of its constituent objects and systems from the standpoint of their self-development and improvement. It is closely connected to the system analysis that introduces regularity, completeness and complexity in the process of innovation management.

In other words, innovation processes of different scale and level form the basis for the development of activity systems. Studying the features of innovation processes in industrial, scientific, technical and organizational systems is the basis for increasing the effectiveness of innovation management. 
In the dynamic system of the innovation process, subsystems (stages) of the creation, production, and consumption of innovation are distinguished. The stage of creating innovation requires the emergence of a new idea, new knowledge, the use of new equipment, new technology, new materials to produce the idea into a prototype model [3]. The stage of scientific and technical implementation of innovations is the result of engineering developments, laboratory tests, creation of design documentation, production of experimental and prototypes, and technological preparation of production. Distribution, diffusion and commercialization of innovations in the market conditions allow obtaining of the expected effect (Fig. 2).

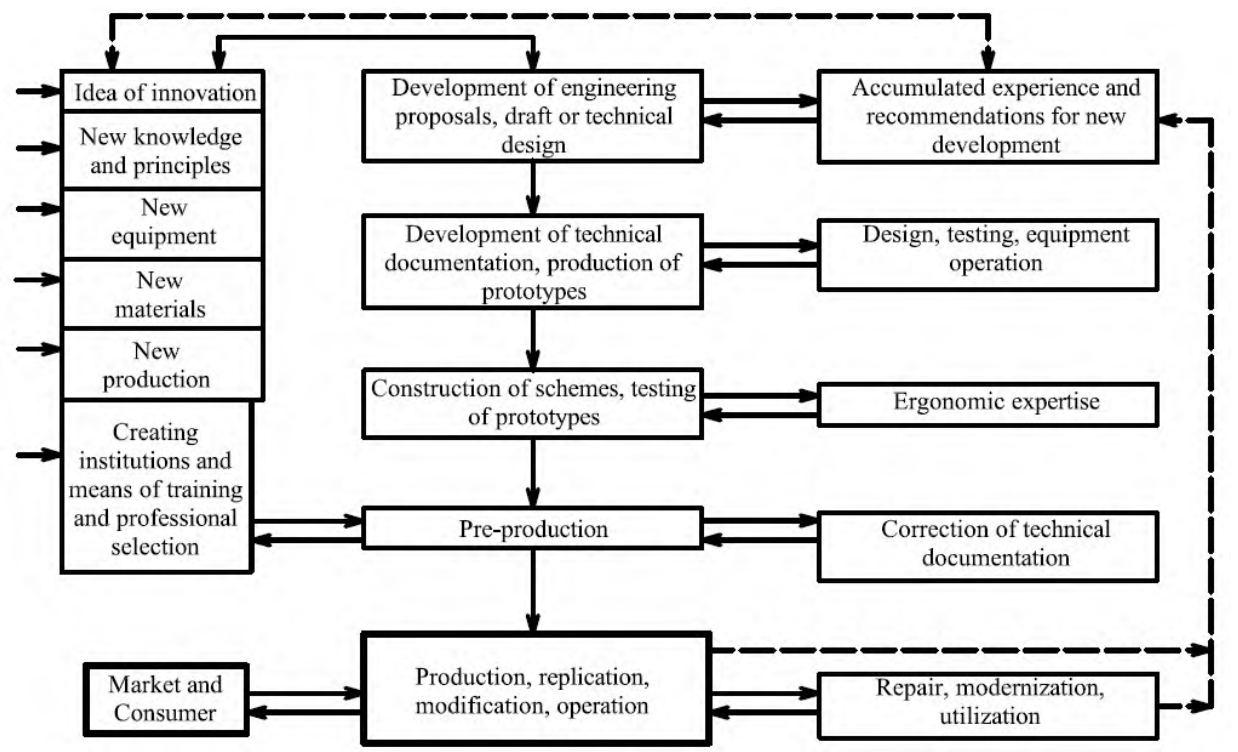

Fig. 2. Generalized scheme of life cycle of innovation.

Stimulating the use of innovations in production is associated with the problem of their correct choice. The variety of possible impact of each of the innovative solutions offered by science and technology creates the complexity of their selection for manufacturing application. Even if several innovations bring the same production effect, they have unequal economic efficiency; differently affect changes in the production apparatus and the materials used, and the organization of production.

The urgency of the problem of choosing the object of innovation is that the correct initial choice predetermines the entire course of the subsequent innovation activity and makes the development of production irreversible.

\section{Results}

Innovations are an essential integral part of construction as a branch of business. This situation exists because of the relative duration of the construction of buildings and structures, as well as due to the fact that construction projects, as a rule, are being built and rebuilt with the prospect of operating them for decades (and sometimes centuries).

Recently, the primary erection of buildings and structures in urban areas (when construction is carried out on previously unbuilt territories) has become rare: the price for land, newly erected or reconstructed utilities and transport routes and roads has risen sharply. More often, they carry out construction of buildings and their reorganization on the already built-up territories (redevelopment, often with the demolition of existing buildings) $[4,5]$. 
This allows us to consider the redevelopment, in relation to the previously built-up areas, as an innovation (urban planning, technical, technological, economic, etc.).

Therefore, it is reasonable to consider the innovative investment and construction life cycle of an object (Pic. 3.) as a combination of a series of successive stages (cycles) and their subcycles during the period from the inception of the idea of the initial construction of a building or structure until its demolition, complete disassembly, disposal of construction and demolition waste (CDW) and non-recyclable part of them.

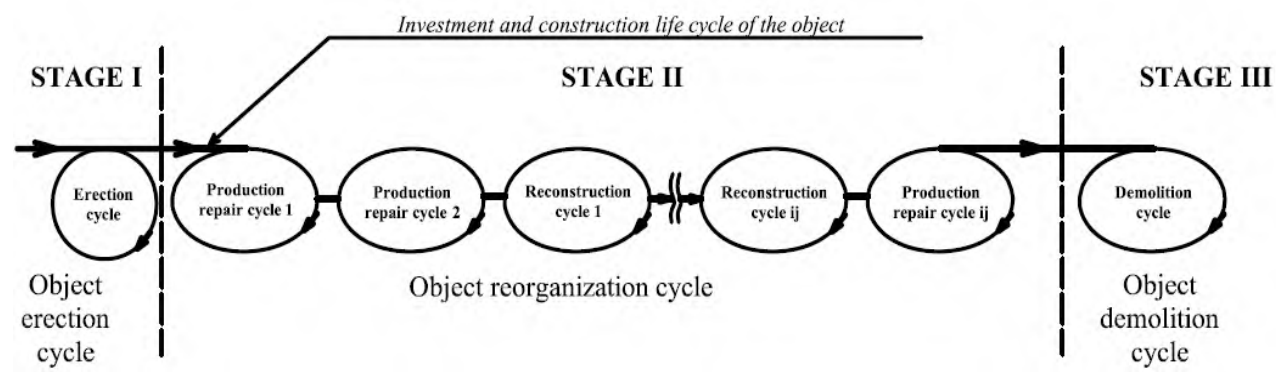

Fig. 3. Infographic model of the innovation life cycle (ILC) of the construction project.

Erection of the construction object (and the cycle of erection of the object, realized at this stage); the content and sequence of implementation of enlarged sub-stages of stage I (from I.1 to I.10 inclusive) are shown in Figure 4;

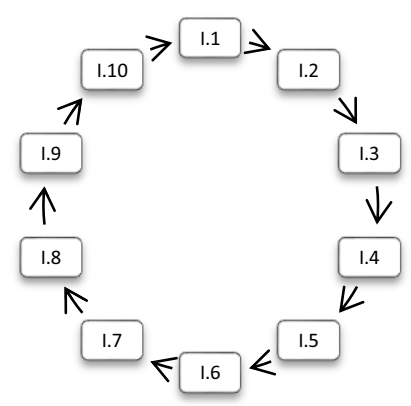

Fig. 4. Notation conventions:

I.1 - development of technical specifications (TS) for the erection of the object (building or structure);

I. 2 - development of a business plan;

I.3 - development of a constructive project for the future facility;

I.4 - development of the project of the organization of construction (POC);

I. 5 - tendering and auctions (tender), objectification of the general contractor (developer);

I.6 - development of working documentation for the construction object;

I.7 - development of the project of production of works (PPW);

I. 8 - development of a work organization project (WOP);

I. 9 - construction and installation works (the actual construction of the object);

I. 10 - acceptance of the object and (if necessary) auction for the sale of the object.

- Stage II: Reorganization of the construction object (and the cycle of reorganization of the object, implemented at this stage Creorganization);

- Stage III: Demolition and disposal of the construction object (and the cycle of demolition of the object, implemented at this stage Cdemolition). 
The basis of the innovation life cycle (ILC) is a calendar organizational and technological design and planning (COTDP) of construction and assembly processes, supported by timely investment.

COTDP is hierarchical functional database accompanying the construction object throughout its innovation life cycle, which reflects all changes in the construction object without any exception, i.e. local adjustments to the constructive project of the construction object of organizational and technological projects: project of the organization of construction (POC), project of production of works (PPW), and work organization project (WOP).

\section{Discussion and conclusions}

During the life cycle, the state of the object is modified. The flexibility of modern building production is a natural result of the variety of types of construction products, natural, social and technical factors influencing the choice of constructive and technological solutions.

The efficiency of the construction industry is due to the desire to obtain high-quality construction products with the lowest consumption of material, financial, labor, time resources.

Hierarchical functional database COTDP should be a market product inalienable from the construction project (subject to continuous organizational and technological, software and computer maintenance and support), with market value and being transferred from owner to owner of the construction object as the object is being sold and purchased up to the stage of its demolition and recycling.

Only with this approach, each new owner (or operator) of a construction object must treat it consciously and make decisions, possessing all the necessary information about its history and current state of engineering systems of a building or structure, as well as its premises and redevelopment.

And only after the completion of the stage of demolition and disposal of the construction object, the hierarchical functional database COTDP can be officially discarded. Although in this case, it is of archival and historical town-planning value.

\section{References}

1. A. Komar, A. Kalgin, M. Fakhratov, O. Kikawa, V. Baev, V. Tsyro, Design and reconstruction of enterprises of precast concrete, (Triada Publishing House LLC, Tver, 2012)

2. A. Kalgin, M. Fakhratov, O. Kikawa, Advanced technologies in the production of building materials. (Publishing House International Concrete Manufacturing LLC, Tver, 2009)

3. A. Kalgin, M. Fakhratov, V. Chulkov, Production and use of building materials, products and systems: Volume 1 . Finishing materials, products and systems. 2nd edn. SVR-ARGUS LLC, (Moscow, 2009)

4. V. Chulkov, Reconstruction: Organizational and anthropotechnical reliability of construction. A series of "Infographic basis of functional systems". SVR-ARGUS LLC, (Moscow, 2012)

5. A. Kalgin, V. Sohryakov, M. Fakhratov, V. Chulkov, Production and use of building materials, products and systems: Volume 4. Production of building structures of precast concrete. Design and reconstruction of enterprises. 2nd edn. SVR-ARGUS LLC, (Moscow, 2012). 